\title{
OTOLOGY
}

\section{Inhibitory effect of mesna and 5-fluorouracil on propylene glycol-induced cholesteatoma in rats}

\author{
Gli effetti inibitori del mesna e 5-fluorouracile nel colesteatoma indotto \\ dal glicol-propilene nei topi \\ Numan Kokten¹, Ozan Tuysuz ${ }^{1}$, Tulay Zenginkinet², Fatih Mehmet Hanege ${ }^{1}$, Mahmut Tayyar Kalcioglu \\ ${ }^{1}$ Istanbul Medeniyet University, Faculty of Medicine, Goztepe Training and Research Hospital, Department of Otorhinolaryngology, \\ Istanbul, Turkey; ${ }^{2}$ Istanbul Medeniyet University, Faculty of Medicine, Goztepe Training and Research Hospital Department of \\ Pathology, Istanbul, Turkey
}

\section{SUMMARY}

Objective. The aim of this study was to investigate the inhibitory effect of different doses of sodium-2-mercaptoethanesulphonate (MESNA) and 5-fluorouracil on cholesteatoma formation. Methods. Fifty-six Wistar albino male rats were divided into seven groups with eight rats in each. On the first, eighth and fifteenth days, $0.2 \mathrm{ml}$ of saline was administered to the group 1 (control group), and propylene glycol to induce cholesteatoma the other groups. On the $22^{\text {nd }}$ day of the study, $0.2 \mathrm{ml}$ saline was given to Group 1 and Group 2. Groups 3 to 7 were treated with $0.2 \mathrm{ml} \mathrm{100 \%} \mathrm{MESNA,} 0.2 \mathrm{ml} 50 \%$ MESNA, $0.2 \mathrm{ml} 20 \%$ MESNA, $0.2 \mathrm{ml}$ 5-fluorouracil and $0.1 \mathrm{ml} 100 \%$ MESNA plus $0.1 \mathrm{ml} 5$-fluorouracil, respectively, with all applications performed by intratympanic injection.

Results. Significant differences were found between Group 1 and all other groups except Group 3. Significant differences were also found between Group 3 and Groups 2,5 and $6(\mathrm{P}<0.05)$. Conclusions. According to the results of this study, experimental cholesteatoma induced with propylene glycol may be inhibited by MESNA at 100\% concentration.

KEY WORDS: sodium-2-mercaptoethanesulphonate, MESNA, 5-fluorouracil, cholesteatoma

\section{RIASSUNTO}

Obiettivo. Lo scopo di questo studio era di indagare l'effetto inibitorio dell'applicazione di diverse dosi di sodio-2-mercaptoetansolfonato (MESNA) e 5-fluorouracile sulla formazione di colesteatoma.

Metodi. Cinquantasei ratti maschi albini Wistar sono stati divisi in sette gruppi da otto ratti ciascuno. Il primo, l'ottavo e il quindicesimo giorno, sono stati somministrati $0,2 \mathrm{ml}$ di soluzione salina al gruppo 1 (gruppo di controllo) e glicole propilenico per indurre il colesteatoma negli altri gruppi. Il $22^{\circ}$ giorno dello studio, sono stati somministrati $0,2 \mathrm{ml}$ di soluzione salina al Gruppo 1 e al Gruppo 2. I gruppi da 3 a 7 sono stati trattati con 0,2 $\mathrm{ml}$ di MESNA al 100\%, 0,2 $\mathrm{ml}$ di MESNA al 50\%, 0,2 $\mathrm{ml}$ di MESNA al 20\%, 0,2 $\mathrm{ml}$ di 5-fluorouracile e 0,1 ml di MESNA al 100\% più 0,1 $\mathrm{ml}$ di 5-fluorouracile, rispettivamente, con tutte le applicazioni eseguite mediante iniezione intratimpanica.

Risultati. Sono state trovate differenze significative tra il Gruppo 1 e tutti gli altri gruppi eccetto il Gruppo 3. Differenze significative sono state trovate anche tra il Gruppo 3 e $i$ Gruppi 2, 5 e $6(P<0,05)$.

Conclusioni. Secondo i risultati di questo studio, il colesteatoma sperimentale indotto con glicole propilenico può essere inibito da MESNA a una concentrazione del 100\%.

PAROLE CHIAVE: sodio-2-mercaptoetansolfonato, MESNA, 5-fluorouracile, colesteatoma

\section{Introduction}

Cholesteatoma consists of a matrix of keratinised squamous epithelium, subepithelial connective tissue and a perimatrix of keratin debris ${ }^{1}$. The treatment
Received: January 16, 2021

Accepted: April 19, 2021

\section{Correspondence}

Mahmut Tayyar Kalcioglu

Istanbul Medeniyet University, Faculty of Medicine, Department of Otorhinolaryngology, Goztepe Training and Research Hospital, 34722 Istanbul, Turkey

Tel. +90 2165709070 . Fax +90 2165666614

E-mail: mtkalcioglu@hotmail.com

Funding

None.

Conflict of interest

The Authors declare no conflict of interest.

How to cite this article: Kokten N, Tuysuz $\mathrm{O}$, Zenginkinet $\mathrm{T}$, et al. Inhibitory effect of mesna and 5-fluorouracil on propylene glycolinduced cholesteatoma in rats. Acta Otorhinolaryngol Ital 2021;41:481-486. https://doi. org/10.14639/0392-100X-N1392

(c) Società Italiana di Otorinolaringoiatria e Chirurgia Cervico-Facciale

\section{cc) (i) $\Theta$}

This is an open access article distributed in accordance with the CC-BY-NC-ND (Creative Commons Attribution-NonCommercial-NoDerivatives 4.0 International) license. The article can be used by giving appropriate credit and mentioning the license, but only for non-commercial purposes and only in the original version. For further information: https:// creativecommons.org/licenses/by-nc-nd/4.0/deed.en 
of cholesteatoma is surgical, but recent research into agents such as sodium-2-mercaptoethanesulfonate (MESNA) and 5-fluorouracil (5-FU) have been carried out ${ }^{2-5}$.

The synthetic sulphur compound MESNA is the sodium salt of the 2-thiosulphonate anion and acts by breaking down disulphide bonds ${ }^{2,6,7}$ and is widely used in medicine because of its protective, mucolytic and antioxidant effects ${ }^{7}$. It has been safely used in the treatment of various conditions, including cyclophosphamide-induced hemorrhagic cystitis as a cell protector, respiratory diseases such as asthma, laryngitis, chronic bronchitis and rhinitis as a mucolytic agent, as a protective agent in pulmonary diseases against the toxicity of some chemotherapeutics and in the surgery of chronic otitis media with cholesteatoma. As a thiol compound, it acts by breaking the disulphide bonds of the epithelium and facilitating dissection and is used in the surgery of atelectatic ears and chronic otitis media with cholesteatoma ${ }^{2,8,9}$. It helps lateralisation of the eardrum in atelectatic ears, easier dissection of cholesteatoma matrix and decreases residual cholesteatoma risk ${ }^{2-4,6,7}$. It was recently reported that use of MESNA in tympanosclerosis surgery provided easy dissection of plaques and prevented new sclerotic plaque formation due to its antioxidant and dissector effects ${ }^{10}$. The main concern of any drug application is the possibility of complications and toxicity, and MESNA application does not seem to have any side effects on the middle ear, hearing, cochlea, or facial nerve ${ }^{7-9}$.

The antimetabolite 5-FU is used in cancer chemotherapy, precancerous lesions and benign skin lesions and exerts its effect by inhibiting thymidylate synthase, which converts ribonucleotides into deoxyribonucleotides, blocking DNA synthesis ${ }^{11,12}$. It affects cells in the growth phase synthesising DNA and RNA and has no effect on static cells ${ }^{12}$. There are studies suggesting the use of 5-FU as an antineoplastic agent that suppresses cell proliferation in the treatment of otitis media with cholesteatoma ${ }^{5,12}$.

Cholesteatoma treatment is important in otologic surgery and treatment modalities need to be improved.

The aim of this study was to investigate the inhibitor effects of MESNA and 5-FU on cholesteatoma created by propylene glycol. Although the effects of these chemicals on cholesteatoma were discussed in different studies, we aimed to investigate the effects of these agents at different concentrations as well as investigating possible synergistic effects by using them together.

\section{Materials and methods}

The approval was obtained from the Local Experimental Animals Ethics Committee (YUHDEK:639-01.02.2018). The study was performed in the animal laboratory on 56
Wistar albino male rats weighing 225 to 360 grams, divided into seven groups of eight rats each. Weight measurements were made to create standard rat groups. A total of 100 ears (50 right and 50 left) were evaluated. Group 1 was the saline control group in which $0.2 \mathrm{ml}$ of saline was applied to both ears of the rats on days 1,8 and 15 . Rats in the other groups were treated with $0.2 \mathrm{ml}$ of $100 \%$ propylene glycol on days 1,8 and 15 to induce cholesteatoma. On the 22 nd day of the study, $0.2 \mathrm{ml}$ saline was administered to Groups 1 and 2. Group 3 was treated with $0.2 \mathrm{ml} 100 \%$ MESNA (Uromitexan, $400 \mathrm{mg}$ Eczacibasi-Baxter Oncology Drug, Istanbul, Turkey), Group 4 was treated with $0.2 \mathrm{ml} 50 \%$ MESNA, Group 5 was treated with $0.2 \mathrm{ml} 20 \%$ MESNA, Group 6 was treated with $0.2 \mathrm{ml} 5$-FU (5-fluorouracil Biosyn $5 \mathrm{Ml} 250 \mathrm{Mg}$, Orna Drug, Istanbul, Turkey) and Group 7 was treated with $0.1 \mathrm{ml} 100 \%$ MESNA plus $0.1 \mathrm{ml} 5$-FU. During these procedures, rats were anaesthetised by intraperitoneal injection with $100 \mathrm{mg} / \mathrm{kg}$ ketamine and $10 \mathrm{mg} /$ $\mathrm{kg}$ xylazine hydrochloride. In this study, all applications were performed by intratympanic injections with a surgical microscope.

Only 4 rats were lost due to respiratory arrest during the procedures and 2 rats were lost during follow-up, and thus the study was completed with 50 rats. Twelve weeks after the last intratympanic injection, animals were euthanised with a high dose of intraperitoneal ketamine. Both the right and left temporal bones of each animal were removed for histopathological examination.

\section{Histopathological examination}

After the temporal bones were fixed with $10 \%$ formaldehyde, they were decalcified with $10 \%$ nitric acid. The sections were embedded in paraffin using standard techniques, and the $4 \mathrm{~mm}$ thick sections were prepared and stained with haematoxylin-eosin (H\&E). All specimens were evaluated by a pathologist blinded to each group. Tympanic membrane, middle ear mucosa and bulla were histopathologically evaluated with a microscope (Olympus BX 51, Olympus, Japan), with samples evaluated for parameters such as cholesteatoma characterised by the presence of keratinised squamous epithelium in the middle ear cavity (Fig. 1), granulation tissue (Fig. 2), and cyst formation, fibrosis and acute inflammation in the bulla (Fig. 3). The presence of keratinised squamous epithelium in the middle ear cavity was accepted as positive for cholesteatoma and vice versa as negative. Any suspicious finding was also evaluated as negative.

\section{Statistical analysis}

Data were evaluated using SPSS 20.0. Percentage, mean, standard deviation and frequency values were calculated. 


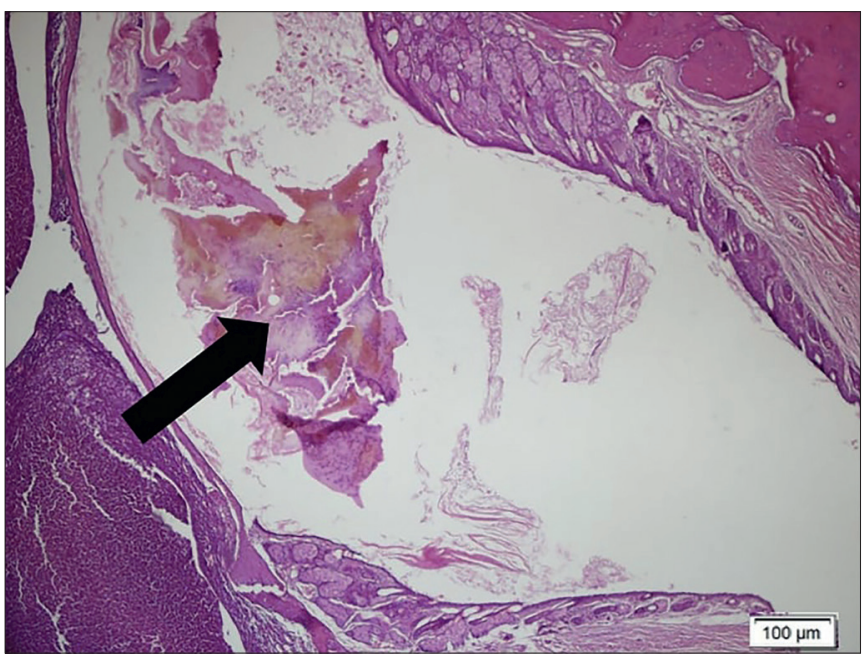

Figure 1. Cholesteatoma and keratin debris characterised by the presence of keratinised squamous epithelium in the middle ear cavity (Haematoxylin \& Eosin, 100X).

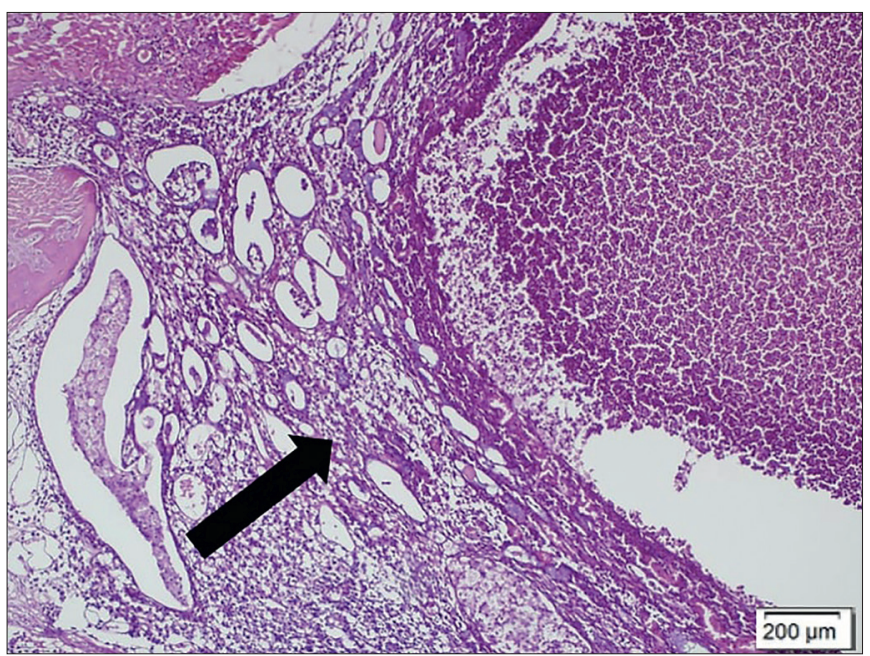

Figure 2. Granulation tissue formation (Haematoxylin \& Eosin, 200X).

The relationship between categorical variables was evaluated using the Chi-square test. $\mathrm{P}<0.05$ was considered significant in all analyses.

\section{Results}

\section{Cholesteatoma development}

As mentioned in the Methods, the presence of keratinised epithelium in the middle ear was accepted as cholesteatoma. In Group 1, the saline control, cholesteatoma was not observed in any of the 16 ears. Cholesteatoma development was observed in $13(81.2 \%)$ ears of Group 2 as the propylene glycol control, three ears (21.4\%) in Group 3, nine ears $(64.3 \%)$ in Group 4, 11 ears (78.6\%) in Group 5, 12 ears

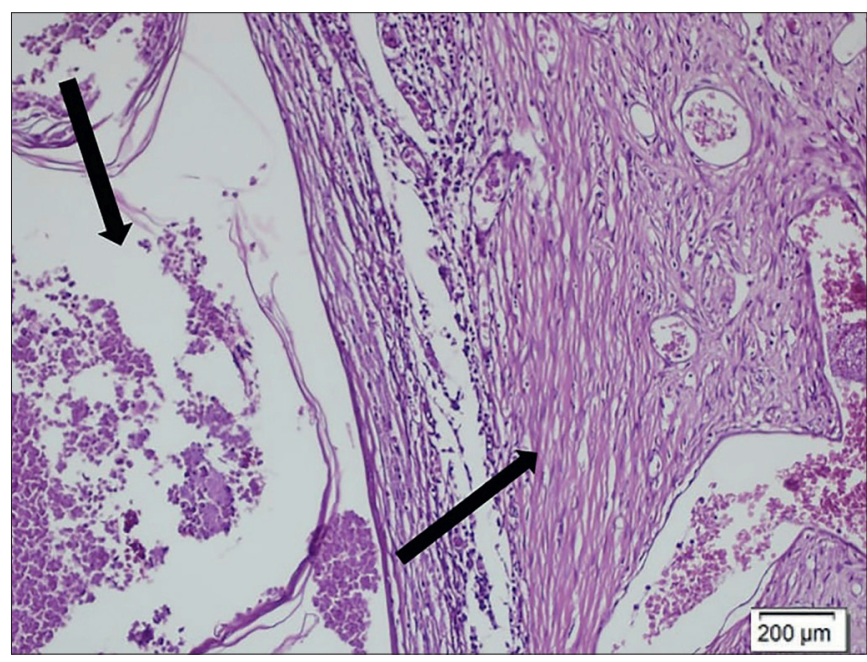

Figure 3. Cyst formation in the bulla, fibrosis, appearance of acute inflammation (Haematoxylin \& Eosin, 200X). Left marked arrow: Cystic space view, Right marked arrow: Fibrosis.

(85.7\%) in Group 6 and seven ears (58.3\%) in Group 7. Significant differences were found between Group 1 and all other groups except Group 3, which was treated with $100 \%$ MESNA. Significant differences were also found between Group 3 and Groups 2, 5 and $6(\mathrm{P}<0.05)$. The difference was not statistically significant in all other pairwise comparisons $(\mathrm{P}>0.05)$ as shown in Table I.

\section{Other findings}

When epithelial hyperplasia was compared, significant differences were found between Group 1 and all other groups $(p<0.05)$ except group $3(p=0.140)$. Significant differences were also found between Group 3 and Group $2(p=0.001)$ (Tab, II). While there was a significant difference between the Group 1 and all of the other groups in terms of fibrosis except Group 4 and 5 ( $\mathrm{p}<0.05)$, no significant difference was found when the groups were compared with Group 2 ( $p>0.05)$ as shown in Table II. There were significant differences between Group 1 and all groups in terms of granulation tissue formation $(\mathrm{p}<0.05)$. However, no significant difference was observed when all groups were compared to Group 2 ( $p>0.05$ ) (Tab. II). There was a significant difference in cyst formation between the Group 1 and all of the other groups except Groups 2, 4 and $6(\mathrm{p}<0.05)$, and no significant difference was found when all groups were compared with Group 2 (P > 0.05) (Tab. II).

\section{Discussion}

Cholesteatoma, as a hyperplastic keratinised flat epithelium located in the middle ear and mastoid bone, causes osteo- 
Table I. Results of control and treatment groups for cholesteatoma formation.

\begin{tabular}{lccccccc} 
& 1. Group & 2. Group & 3. Group & 4. Group & 5. Group & 6. Group & 7. Group \\
1. Group & & 0.000 & 0.225 & 0.001 & 0.000 & 0.000 & 0.005 \\
2. Group & 0.000 & & 0.003 & 0.417 & 1.00 & 1.00 & 0.231 \\
3. Group & 0.225 & 0.003 & & 0.054 & 0.007 & 0.002 & 0.105 \\
4. Group & 0.001 & 0.417 & 0.054 & & 0.678 & 0.385 & 0.756 \\
5. Group & 0.000 & 1.00 & 0.007 & 0.678 & & 1.00 & 0.401 \\
6. Group & 0.000 & 1.00 & 0.002 & 0.385 & 1.00 & & 0.190 \\
7. Group & 0.005 & 0.231 & 0.105 & 0.756 & 0.401 & 0.190 & \\
\hline
\end{tabular}

Table II. Comparison results of control and treatment groups for epithelial hyperplasia, fibrosis, granulation tissue and cyst formation in bulla.

\begin{tabular}{lccccccc} 
Chi-square test & Groups & 2 & 3 & 4 & 5 & 6 & 7 \\
Epithelial hyperplasia & 1 & 0.000 & 0.140 & 0.001 & 0.000 & 0.000 & 0.007 \\
Fibrosis & 2 & & 0.001 & 0.263 & 0.605 & 0.567 & 0.183 \\
& 1 & 0.01 & 0.013 & 0.14 & 0.280 & 0.013 & 0.002 \\
Granulation tissue formation & 2 & & 0.961 & 0.183 & 0.086 & 0.961 & 0.445 \\
& 1 & 0.001 & 0.000 & 0.000 & 0.000 & 0.002 & 0.000 \\
Cyst formation & 2 & & 0.648 & 0.552 & 0.552 & 0.433 & 0.611 \\
& 1 & 0.441 & 0.021 & 0.133 & 0.021 & 0.462 & 0.034 \\
& 2 & & 0.116 & 0.426 & 0.116 & 0.550 & 0.160 \\
\hline
\end{tabular}

clastic activity and bone resorption. Because of these effects, it can lead to hearing loss, facial paralysis, vestibular disorders and even fatal complications such as meningitis and brain abscessation ${ }^{1,2,4}$. The treatment for cholesteatoma is surgical dissection, but non-surgical treatment modalities for cholesteatoma have been the subject of research in recent years.

Cholesteatoma can be induced in laboratory animals by applying propylene glycol to the middle ear ${ }^{4,11,13-20}$. The irritation caused by propylene glycol in the middle ear mucosa creates an inflammatory response and leads to hyperplasia of the epidermal and connective tissue layers of the tympanic membrane. Hyperplastic epidermis reaches the middle ear cavity by penetrating the intact tympanic membrane, proliferation and keratinisation continues and cholesteatoma develops ${ }^{11,20}$. The success rate of induced cholesteatoma varies depending on the propylene glycol concentration, the number of applications and the species of laboratory animal used ${ }^{20}$. Vassalli et al. reported cholesteatoma in four of seven ears treated with $10.5 \%$ of propylene glycol and no cholesteatoma treated with $2 \%$ propylene glycol in chinchillas ${ }^{21}$. Kayhan et al. reported no cholesteatoma formation treated with $60 \%$ propylene glycol in nine ears of guinea pigs. They attributed this result to single dose administration and the low concentration of propylene glycol in the middle ears of the guinea pigs ${ }^{20}$. Sennaroglu et al. reported 33\% cholesteatoma formation treated with $50 \%$ propylene glycol applied three times with an interval of five days in rats ${ }^{14}$. The number of propylene glycol applications is also important in the formation of cholesteatoma, in most of these studies, propylene glycol was applied more than three times $4,11,13,16,17,19$. In most of these studies, propylene glycol was applied to the middle ears of experimental animals, reaching the bulla surgically and the rate of cholesteatoma development had been reported as 0 to $100 \%{ }^{4,11,13-20}$. Intratympanic application is another choice. By using this method, Melo et al. ${ }^{15}$ and Ismi et al. ${ }^{4}$ reported cholesteatoma development rates of $63.6 \%$ and $88 \%$, respectively.

In the current study with the same method, a cholesteatoma development rate of $81.2 \%$ was observed. In experimental studies, inhibitory effects of several compounds have been investigated in propylene glycol-induced cholesteatoma. Chemicals such as trans-retinoic acid, MESNA, 5-FU, intratympanic corticosteroid have been shown to inhibit propylene glycol-induced cholesteatoma ${ }^{4,11,13,14}$. No significant inhibitory effects of mitomycin $\mathrm{C}$, hyaluronic acid, systemic naproxen sodium, cyclophosphamide, isotretinoin, or systemic corticosteroid have been demonstrated on propylene glycol-induced cholesteatoma ${ }^{15-20}$.

MESNA breaks down the disulphide bonds in the cholesteatoma matrix, allowing the cholesteatoma to be removed more easily and reduces residual cholesteatoma risk ${ }^{2}$. Ismi et al. reported that development of propylene glycol-in- 
duced cholesteatoma was inhibited by a single dose of $10 \%$ MESNA ${ }^{4}$. Ismi et al. also found a cholesteatoma formation rate of $88 \%$ and this was very low in the MESNA group. They reported single dose intratympanic MESNA application inhibited propylene glycol-induced cholesteatoma via its antioxidant effect and disturbing the disulphide bonds of keratin filaments ${ }^{4}$.

Smith used 5-FU in the treatment of cholesteatoma for the first time in the literature and reported its clinical effects, where 76 open mastoid or middle ear cholesteatoma patients were treated with topical use of 5-FU in addition to surgery ${ }^{22}$ and concluded that topical 5-FU can be used in hyperkeratosis, external ear canal, mastoid and middle ear cholesteatoma management with very few side effects. Wright et al. reported that 5-FU inhibited the development of experimental cholesteatoma induced by propylene glycol in chinchillas by reducing the proliferation of the epidermal and connective tissue of tympanic membrane ${ }^{11}$. Takahashi et al. reported that topical 5-FU cream was applied to 50 ears of 50 patients with various types of cholesteatoma, two or five times at two-week intervals. It was concluded that topical 5-FU cream was effective in the clinical treatment of cholesteatoma; no serious side effects were observed and the cream could be used in the treatment of early stage disease or in patients who could not be operated on for various reasons ${ }^{23}$. No side effects related to ototoxicity have been reported in high-dose intravenous 5-FU applications in chemotherapy ${ }^{12}$, and minimal doses of topical use of 5-FU should be safe. Yamamato et al. showed that after the use of topical 5-FU in attic cholesteatoma, clinical inhibition of cholesteatoma occurred due to downregulation of keratinocyte growth factor in cholesteatoma stromal cells and a decrease in proliferative activity in epithelial cells. They suggested to use 5-FU in early stage cholesteatoma patients with computed tomography follow-up ${ }^{24}$.

Successful results of the use of 5-FU and MESNA alone in the treatment and prevention of cholesteatoma formation have been reported in several studies ${ }^{2-4,11,22-24}$. In our study, we wanted to observe whether using these drugs together would create a synergistic effect. However, unlike that reported in the literature, we could not detect the inhibitory effect of 5-FU alone by itself or in combination with MESNA.

This study investigated the use of $0.2 \mathrm{ml} 5$-FU (Group 6) and $0.1 \mathrm{ml} \mathrm{100 \%} \mathrm{MESNA} \mathrm{plus} 0.1 \mathrm{ml} 5$-FU combination (Group 7), against cholesteatoma development. A significant inhibitory effect of 5-FU alone and in combination with MESNA against cholesteatoma development $(\mathrm{P}>0.05)$ could not be shown.

The effects of propylene glycol on the middle ear have been investigated by several researchers ${ }^{4,11,13-20}$. These have used a range of propylene glycol concentrations from two to $100 \%$, different application intervals, different experimental animals including chinchillas, guinea pigs and rats and different surgical techniques, including bulla and intratympanic ${ }^{4,11,13-20}$, and thus it is difficult to compare the results. All studies have shown that the irritation caused by propylene glycol produces chronic inflammation in the middle ear, bulla, the tympanic membrane and all tissues of the ear. These changes vary from inflammatory mucosal changes to bone erosion such as epithelial hyperplasia, fibrosis, oedema, haemorrhage, effusion, granulation tissue formation, cochlear bone erosion, cyst formation, cholesteatoma development, perforation of tympanic membrane, thickening of tympanic membrane, osteogenesis, thickening of bone, fibrous adhesions and erosion of inner ear structures ${ }^{4,11,13-20}$. Several chemicals have been investigated to find a protective effect against these changes. Ismi et al. reported single dose MESNA application inhibited cholesteatoma development in propylene glycol-induced cholesteatoma, but they did not find significant differences in granulation tissue formation, cyst formation, epithelial hyperplasia and fibrosis ${ }^{4}$. In this study, the inhibitory effect of single dose $100 \%$ MESNA against cholesteatoma $(p=0.003)$ and epithelial hyperplasia $(p=0.001)$ was significant. There were no significant differences in granulation tissue formation, cyst formation, and fibrosis ( $\mathrm{P}>0.05)$. It is hypothesised that the inhibition of epithelial hyperplasia by $100 \%$ MESNA is due to its antioxidant properties. This study agrees with Ismi et al. ${ }^{4}$ that MESNA application inhibits propylene glycol-induced cholesteatoma via its antioxidant effect and during cholesteatoma development, it blocks formation of a stable structure by disrupting the stabilisation and organisation of filaments by breaking down disulphide bonds. In this study, the effects of $100 \%, 50 \%$, and $20 \%$ MESNA, 5-FU and 100\% MESNA plus 5-FU administration on cholesteatoma development were investigated. Only $100 \%$ MESNA administration produced significant results in inhibition of propylene glycol-induced experimental cholesteatoma development and epithelial hyperplasia $(\mathrm{P}<0.05)$. Other MESNA concentrations and combination with 5-FU did not produce a significant inhibitory effect against cholesteatoma development.

\section{Conclusions}

According to the results of the current study, experimental cholesteatoma induced with propylene glycol can be inhibited by MESNA at $100 \%$ concentration. Diluted doses of MESNA, 5-FU, and the combination of these two have insufficient inhibitory effects against cholesteatoma. This study shows that the use of undiluted MESNA may prevent cholesteatoma development and pave the way for medical 
treatment of cholesteatoma. These results should be supported by further experimental studies and clinical trials.

\section{References}

1 Yung M, Tono T, Olszewska E, et al. EAONO/JOS Joint Consensus Statements on the definitions, classification and staging of middle ear cholesteatoma. J Int Adv Otol 2017;13:1-8. https://doi.org/10.5152/ iao.2017.3363

2 Kalcioglu MT, Cicek MT, Bayindir T, et al. Effectiveness of MESNA on the success of cholesteatoma surgery. Am J Otolaryngol 2014;35:357-361. https://doi.org/10.1016/j.amjoto.2014.01.002

3 De la Torre C, Villamor P. Chemically assisted dissection with sodium 2-mercaptoethanesulfonate (MESNA) in the surgical management of pediatric cholesteatoma. Otol Neurotol 2019;40:645-650. https://doi. org/10.1097/MAO.0000000000002174.

4 Ismi O, Karabulut YY, Bal KK, et al. Single dose intratympanic mesna application inhibits propylene glycol induced cholesteatoma formation. Laryngol Otol 2017;131:215-220. https://doi.org/10.1017/ S002221511600983X

5 Takahashi H, Funabiki K, Hasebe S, et al. Clinical efficacy of 5-fluorouracil (5-FU) topical cream for treatment of cholesteatoma. Auris Nasus Larynx 2005;32:353-357. https://doi.org/10.1016/j. anl.2005.05.015

6 Yilmaz M, Goksu N, Bayramoglu I, et al. Practical use of MESNA in atelectatic ears and adhesive otitis media. ORL J Otorhinolaryngol Relat Spec 2006;68:195-198. https://doi.org/10.1159/000091472

7 Eğilmez OK, Kökten N, Baran M, et al. Electrophysiological and histopathological evaluation of effects of sodium-2 mercaptoethanesulfonate used for middle ear surgery on facial nerve functions. J Int Adv Otol 2018;14:239-244. https://doi.org/10.5152/iao.2017.3888

8 Vincenti V, Mondain M, Pasanisi E, et al. Cochlear effects of mesna application into the middle ear. Ann N Y Acad Sci 1999;884:425-432. https://doi.org/10.1111/j.1749-6632.1999.tb08659.x

9 Van Spaendonck MP, Timmermans JP, Claes J, et al. Single ototopical application of mesna has no ototoxic effects on guinea pig cochlear hair cells: a morphological study. Acta Otolaryngol 1999;119:685689. https://doi.org/10.1080/00016489950180630

10 Eren SB, Dogan R, Vural Ö, et al. Use of mesna in the treatment of ossicular chain fixation related to tympanosclerosis; prospective, clinical study. Am J Otolaryngol 2020;41:102506. https://doi. org/10.1016/j.amjoto.2020.102506

11 Wright CG, Bird LL, Meyerhoff WL. Effect of 5-fluorouracil in cholesteatoma development in an animal model. Am J Otolaryngol 1991;12:133-138. https://doi.org/10.1016/0196-0709(91)90142-3

12 Kanemaru S, Nakamura T, Yamashita M, et al. 5-fluorouracil ointment for the treatment of otitis media with effusion. La- ryngoscope 2007;117:215-219. https://doi.org/10.1097/01. mlg.0000248231.62834.e3

13 Antunes ML, Fukuda Y, Penido Nde O, et al. Effect of transretinoic acid in the inhibition of cholesteatoma in guinea pigs. Braz J Otorhinolaryngol 2008;74:53-60. https://doi.org/10.1016/ s1808-8694(15)30751-5

14 Sennaroglu L, Ozkul A, Gedikoglu G, et al. Effect of intratympanic steroid application on the development of experimental cholesteatoma. Laryngoscope 1998;108:543-547. https://doi. org/10.1097/00005537-199804000-00015

15 Melo AA, Caldas Neto SS, Leão FS, et al. Effect of intratympanic mitomycin $\mathrm{C}$ on the development of cholesteatoma and otitis media in rats. J Laryngol Otol 2013;127:359-363. https://doi.org/10.1017/ S002221511300011X

16 White SJ, Wright CG, Robinson KS, et al. Effect of topical hyaluronic acid on experimental cholesteatoma. Am J Otolaryngol 1995;16:312318. https://doi.org/10.1016/0196-0709(95)90059-4

17 Kayhan FT, Algün Z. The effect of naproxen sodium on experimental otitis media. Kulak Burun Bogaz Ihtis Derg 2008;18:14-18.

18 Pownell PH, Wright CG, Robinson KS, et al. The effect of cyclophosphamide on development of experimental cholesteatoma. Arch Otolaryngol Head Neck Surg 1994;120:1114-1116. https://doi. org/10.1001/archotol.1994.01880340058009

19 Jove MA, Vassalli L, Raslan W, et al. The effect of isotretinoin on propylene glycol-induced cholesteatoma in chinchilla middle ears. Am J Otolaryngol 1990;11:5-9. https://doi.org/10.1016/0196-0709(90)90163-p

20 Kayhan FT, Algün Z. The effect of systemic prednisolone on propylene glycol-induced otitis media in guinea pig. Kulak Burun Bogaz Ihtis Derg 2006;16:214-220.

21 Vassalli L, Harris DM, Gradini R, et al. Inflammatory effects of topical antibiotic suspensions containing propylene glycol in chinchilla middle ears. Am J Otolaryngol 1988;9:1-5. https://doi.org/10.1016/ s0196-0709(88)80001-2

22 Smith MF. The topical use of 5-fluorouracil in the ear in the management of cholesteatoma and excessive mucous secretion. Laryngoscope 1985;95:1202-1203. https://doi. org/10.1288/00005537-198510000-00010

23 Takahashi H, Funabiki K, Hasebe S, et al. Clinical efficacy of 5-fluorouracil (5-FU) topical cream for treatment of cholesteatoma. Auris Nasus Larynx 2005;32:353-357. https://doi.org/10.1016/j. anl.2005.05.01

24 Yamamoto-Fukuda T, Terakado M, Hishikawa Y, et al. Topical application of 5-fluorouracil on attic cholesteatoma results in downregulation of keratinocyte growth factor and reduction of proliferative activity. Eur Arch Otorhinolaryngol 2008;265:1173-1178. https://doi. org/10.1007/s00405-008-0597-9 